\title{
Prevalence and Risk Factors of Postpartum Depression in Provincial Area
}

\author{
Ajin Yun, MD, Jeong-Seok Seo, MD, PhD, Beom-Woo Nam, MD, PhD \\ Department of Psychiatry, School of Medicine, Konkuk University, Chungju, Korea
}

Background: Studies on prevalence and social variables affecting postpartum depression appear to be inconsistent. This study aimed to examine the prevalence of postpartum depression, as well as the correlation between education, offspring, age, and risk of the postpartum depression.

Methods: This study included 144 mothers living in Chungju who appeared to experience postpartum depression based on a score of $>10$ marks on the Korean version of the Edinburgh Postnatal Depression Scale (EPDS). Correlation and logistic regression analyses were used to calculate correlation coefficients and odds ratios (OR) for postpartum depression based on the education level of mothers and number of offspring.

Results: Prevalence of postpartum depression was found to be $29.17 \%$. Age was not significantly correlated with EPDS score. EPDS scores tended to decrease with the increase in the number of education years $(\mathrm{OR}, 0.66)$; however, EPDS scores tended to increase with the increase in the number of offspring increased $(\mathrm{OR}, 1.65)$.

Conclusion: The result of this study demonstrates that education acts as a protective factor and number of offspring acts as a risk factor for postpartum depression. It also suggests that proper intervention in the mothers' educational level and number of offspring is necessary.

Keywords Postpartum depression; Prevalence; Education; Offspring; Age

\section{INTRODUCTION}

For female, pregnancy and childbirth are impactful events in their lives. Moreover, they are stressed or troubled by burden of childcare [1]. It is found that the change in the role of a woman who becomes a mother causes great stress and psychological difficulties. The new role as a mother requires them to restructure their own values and activities, and this process needs considerable mental and physical effort [2]. In fact, it is found that considerable number of mothers experience numerous personal problems after giving birth to their children and their marriage satisfaction also decreases [3]. These negative aspects are usually decreased over time [4], but some mothers suffer from sense of social isolation, sleep disorders, sadness, and lack of motivation. In some cases, they even attempt suicide [5]. Depression that occurs about 6 months after the childbirth can be defined as postpartum depression and it is different from major depressive disorders. It is also different from Postpartum Blues, which about $50 \%$ of mothers experience within 3 to 5 days after the childbirth and recover it within a few weeks [6].

The postpartum depression differs from major depressive disorders in various respects [7]. The difference between postpartum depression and major depressive disorder is so insignificant that some studies [8] argue that the postpartum depression should be regarded as a

Received July 1, 2020, Revised August 3, 2020, Accepted September 15, 2020

Correspondence: Beom-Woo Nam, MD, PhD

Department of Psychiatry, School of Medicine, Konkuk University, 268 Chungwon-daero, Chungju 27478, Korea

TEL +82-43-840-8470 E-mail nempty@korea.com ORCID https://orcid.org/0000-0003-3530-1746

Copyright (C) by Korean Society for Affective Disorders. All Rights reserved.

This is an Open Access article distributed under the terms of the Creative Commons Attribution Non-Commercial License (http://creativecommons.org/licenses/ by-nc/4.0/) which permits unrestricted non-commercial use, distribution, and reproduction in any medium, provided the original work is properly cited. 
concept included to major depressive disorder. However, study results supporting the idea to distinguish the postpartum depression from major depressive disorder have been consistently reported. The postpartum depression tends to develop at a younger age [9], and it usually shows a more severe level of social dysfunction [10]. In addition, it is found that mothers with postpartum depression have significantly higher levels of anxieties than female with major depressive disorders, and that longer periods are required to take effect some medications [11]. These study results, which suggest that postpartum depression has its own clinical features, imply that more unique and specific interventions in postpartum depression are required [12].

Furthermore, the postpartum depression not only gives a serious pain to the mother herself, but also negatively affects the lives of other family members including her husband and children [13]. In particular, studies have shown that the negative effects of postpartum depression on new-born babies are extremely critical and its damage may be also significant. The children of mothers suffering from postpartum depression have more emotional and behavioral problems than those of mothers who do not have postpartum depression [14]. In addition to this, their level of social cognitive development also tends to be lower [15]. Moreover, it is found that these negative effects are consistently affecting the children when their mothers no longer show depression symptoms [16]. Mothers who experience postpartum depression have low levels of responses and less interact with their children during the depression period and about one year or more after the childbirth, and the quality of interaction between mothers and their babies is also significantly low [17].

Although the negative effects of postpartum depression are serious as mentioned above, there has been little recognition is needed for the postpartum depression [18]. According to other studies [19], about $80 \%$ of mothers suffering from postpartum depression are not receiving adequate medical treatment because they do not report their psychological difficulties to specialists. This tendency is especially noticeable in Asian countries. Many Asian tend to be reluctant to tell their negative feelings to others, and they regard their depression as a stigma for themselves and their families. Thus, they are more likely to hide their depression than reveal it to other people [18].

Based on these study results, it can be inferred that considerable number of mothers are suffering from postpartum depression but do not receive appropriate treatments. In order to solve this problem, it is necessary to precisely understand the actual state of postpartum depression in Korea and enhance the social interest in it. In foreign countries, the prevalence rate of postpartum depression, including mild one, is reported to range from $20 \%$ to $30 \%$ [20]. Higher prevalence rate is being reported in Korea, but the actual prevalence rate in Korea has not yet been statistically verified as compared to that reported in Western developed countries. In addition, in order to select an appropriate intervention target for postpartum depression, studies on social variables related to the postpartum depression are also required.

To this end, this study examines the prevalence rate of postpartum depression by applying Edinburgh Postnatal Depression Scale (EPDS) to mothers who have given birth less than a month ago in Chungju. In addition, this study also tries to compare the effects of various social variables, such as age of mothers, education years, and the number of children on the postpartum depression.

\section{MATERIALS AND METHODS}

\section{Subjects}

The subjects of this study were 144 mothers who visited the Chungju Health Center from 2015 to 2018 for the purpose of applying for childcare allowance. The mothers were less than a month after giving birth. This study analyzes the results of self-report style scale data collected from them. The inclusion criteria for the subjects were 1) mothers between 19 to 50 years old and 2) mothers able to read and write. The rejection criteria for the subjects were those mothers who had 1) acute mental disease, 2) intellectual disability, 3) organic mental disorder or nervous system disease, and 4) serious physical diseases. In order to protect the mothers' privacy, no personally identifiable information was collected or recorded except for age, number of children, and educational years of the mothers. This study was approved by the Institutional Review Board (IRB No. KUCH 2020 07-023) of Konkuk University of Chungju. This study was exempted from written consent. Because this research using only past medical records has been judged to have extremely low risk to those who are subject to the study. 


\section{Measures Korean version of Edinburgh Postpartum Depression Scale}

This scale consists of 10 questions related to depressive symptoms ( 8 questions) and anxieties ( 2 questions) that are subjectively experienced by the mothers. The subjects are supposed to answer on a 4-point scale (0 to 3 points), and all questions except for question 1, 2, and 4 are reversely scored and summed to calculate the total score [21]. The score ranges from 0 to 30 points, and the higher score means the more serious symptoms of depression. The internal consistency $(\alpha=0.841)$, test-retest reliability $(\mathrm{r}=0.684, \mathrm{p}<0.001)$, and convergent validity $(\mathrm{r}=0.620, \mathrm{p}<0.001$, BAI $\mathrm{r}=0.711, \mathrm{p}<0.001)$ were all confirmed to be good [22].

\section{Statistical analysis}

Based on the EPDS score (cutoff score: 10 points), basic demographic characteristics were analyzed. For comparison, independent t-test or chi-square test was used depending on the characteristics of the data. Through Pearson's correlation analysis and logistic regression analysis, Pearson's correlation coefficient and odds ratio (OR) for age, educational years, and number of children were calculated, and the confidence interval (CI) was set to $95 \%$ and the statistical significance level was set to less than 0.05 . The collected data were analyzed using IBM SPSS Statistics for Windows, Version 25.0 (IBM
Co., Armonk, NY, USA).

\section{RESULTS}

The analysis was conducted targeting a total of 144 subjects, and the basic demographic characteristics of the subjects are presented in Table 1. The EPDS score 10 points were used as cutoff score to distinguish the risk group of postpartum depression from the control group. This study refers to the previous studies that suggested 10.5 [23] and 9.5 points [24] as the optimal cutoff scores of the Asian culture. Based on cutoff score, the percentage of risk group of postpartum depressions was $29.17 \%$ (95\% CI, 22.36-37.05). The number of risk group of postpartum depression was 42 with an average age of $35.12 \pm 5.51$ years and the number of control group was 102 with an average age of $36.02 \pm 4.63$ years. There was no significant difference in age distribution between the two groups $(p=0.318)$. The education years of the risk group of postpartum depressions were $13.87 \pm 1.77$ years, which was lower than the control group (average $15.07 \pm 1.54$ years $)(p<0.05)$. The number of children of the risk group of postpartum depressions was $0.88 \pm 1.02$, which was significantly higher than the control group (average $0.48 \pm 0.78)(\mathrm{p}<0.05)$.

When correlation analysis was performed on age, education years, and number of children for EPDS scores, education years had a negative correlation (Pearson's

Table 1. Demographic variables during pregnancy and postpartum in 144 female, Chungju, Korea

\begin{tabular}{|c|c|c|c|c|}
\hline Demographic variable & $E D P S \geq 10$ & EDPS $<10$ & tor $\chi^{2}$ & $\mathrm{p}$-value \\
\hline Age (y) & $35.12 \pm 5.51$ & $36.02 \pm 4.63$ & -1.003 & 0.318 \\
\hline$<30$ & $8(19.0)$ & $13(12.7)$ & & \\
\hline $31-40$ & $29(69.0)$ & $75(73.5)$ & & \\
\hline$>41$ & $5(11.9)$ & $14(13.7)$ & & \\
\hline Education year & $13.87 \pm 1.77$ & $15.07 \pm 1.54$ & -2.601 & 0.011 \\
\hline$\leq 12$ & $6(40.0)$ & $9(16.7)$ & & \\
\hline $13-14$ & $4(26.7)$ & $7(13.0)$ & & \\
\hline$>15$ & $5(33.3)$ & $38(70.4)$ & & \\
\hline Offspring number & $0.88 \pm 1.02$ & $0.48 \pm 0.78$ & 2.555 & 0.012 \\
\hline 0 & $19(45.2)$ & $67(65.7)$ & & \\
\hline 1 & $13(31.0)$ & $24(23.5)$ & & \\
\hline 2 & $7(16.7)$ & $9(8.8)$ & & \\
\hline$>3$ & $3(7.1)$ & $2(2.0)$ & & \\
\hline
\end{tabular}

Values are presented as mean \pm standard deviation or number (\%).

EDPS, Edinburgh Postnatal Depression Scale. 
Table 2. Correlation between EDPS score and demographic variables

\begin{tabular}{cccc}
\hline Demographic variable & $\rho$ & $R^{2}$ & $p$-value \\
\hline Age & -0.016 & 0.00 & 0.854 \\
Education year & -0.327 & 0.09 & 0.007 \\
Offspring number & 0.223 & 0.04 & 0.007 \\
\hline
\end{tabular}

EDPS, Edinburgh Postnatal Depression Scale; $\rho$, Pearson's correlation coefficient; $R^{2}$, coefficient of determination.

Table 3. OR and 95\% Cls for postpartum depression in relation to selected demographic variables in 144 female, Chungju, Korea

\begin{tabular}{cccc}
\hline Demographic variable & OR $(95 \% \mathrm{Cl})$ & $\mathrm{R}_{\mathrm{N}}{ }^{2}$ & $\mathrm{p}$-value \\
\hline Age & $0.96(0.89-1.04)$ & 0.00 & 0.316 \\
Education year & $0.66(0.47-0.94)$ & 0.12 & 0.019 \\
Offspring number & $1.65(1.10-2.47)$ & 0.06 & 0.016 \\
\hline
\end{tabular}

$\mathrm{OR}$, odds ratio; $\mathrm{Cl}$, confidence interval; $\mathrm{R}_{\mathrm{N}}{ }^{2}$, Nagelkerke's coefficient of determination.

Adjustments were made for age.

correlation coefficient $=-0.327, \mathrm{p}<0.01)$, and the number of children had a positive correlation (Pearson's correlation coefficient $=0.223, \mathrm{p}<0.01$ ). The age of the mothers did not show significant correlation $(\mathrm{p}=0.854)$ with the EPDS score (Table 2).

Table 3 shows the odds ratio and 95\% CI for each variable. The odds ratio of education years was 0.66 $(\mathrm{CI}=0.47-0.94, \mathrm{p}<0.05)$, and the odds ratio of the number of children was $1.65(\mathrm{CI}=1.10-2.47, \mathrm{p}<0.05)$, which was found to be significantly correlated to the postpartum depression. The odds ratio of mothers' age was 0.96 $(\mathrm{CI}=0.89-1.04, \mathrm{p}=0.316$ ), which was not correlated to the postpartum depression.

\section{DISCUSSION}

Using the data collected from mothers living in Chungju, this study examins demographic factors and analyzed relation between the prevalence rate and risk of postpartum depression with each factor by dividing the mothers into risk group and control group based on EPDS scores. Through this study, it is confirmed that as the education level becomes lower and the number of children is higher, the odds ratio of the postpartum depression becomes higher, as well.

First of all, 29.17\% (95\% CI, 22.36-37.05) is the prevalence rate of postpartum depression found in this study. It is about $12 \%$ higher than the prevalence rate $(17 \%)$ in other OECD countries [1]. It is consistent with other studies [18] suggesting that the severity degree of post- partum depression of Asian female is more serious than other race's female. This seems to have resulted from cultural differences about pregnancy and parenting. Traditionally, Korean mothers are responsible for most of the parenting and a large number of mothers quit their jobs either voluntarily or against their will. Based on the fact that the greater the burden of parenting, the higher the likelihood of developing postpartum depression [25], these cultural characteristics of Korea are considered to have a negative effect on the mental health of mothers.

In previous studies, mothers' education level was considered to have no significant correlation with the risk of postpartum depression [26]. However, in numerous studies conducted thereafter, the lower level of education is reported as a risk factor worthy of consideration $[27,28]$. This study could conclude similarly to previous studies. The high correlation between education level and household income is already well-known, and the fact that low household income is a strong predictor of postpartum depression has also been confirmed in other studies on postpartum depression [29].

The correlation between the number of children and postpartum depression is somewhat controversial. In one study, it was found that the prevalence of postpartum depression reached $38 \%$ even in the first childbirth [30]. However, the following other studies revealed that there was a significant correlation between mother of many children and depression [31]. In this study, postpartum depression and the number of children also represent a high odds ratio, which is consistent with the results of previous studies [25] that explained the correlation 
between the burden of parenting and postpartum depression. They suggest that the burden of parenting grow as the number of children increases.

In this study, the age of mothers is found to have no significant correlation with the postpartum depression. Previous studies also reported that there is no correlation between the age of mothers and the postpartum depression [32]. In other previous studies, however, it was found that there was a strong correlation between young ages (usually under 24) and the postpartum depression [9]. It has a limited conclusion, because this study conducted with only 3 mothers (2.1\%) under 24 age compared to previous studies.

In addition to this, there were some other limitations in this study. Firstly, this study was targeted only to mothers who visited the public health center to apply for childcare allowance. Therefore, the mother group who did not visit the public health center or did not receive the childcare allowance in the past was excluded from the study subjects. Moreover, the number of samples was too small compared to the total number of mothers to predict the prevalence. According to the Korea National Statistical Office, the total number of new born babies in Chungju from 2014 to 2018 was 5,247. The number of mothers who participated in this study was 144 , making up only $2.74 \%$ of the population. Consequently, it is difficult to generalize the results of this study to entire female, who are our targeted population. Secondly, the diagnosis of postpartum depression was not diagnosed by a doctor's clinical standard but through self-report questionnaire called Korean version of Edinburgh Postpartum Depression Scale. In this study, only one EDPS score was obtained from mothers within a month of delivery without follow-up. It was difficult to accurately predict the occurrence of depression. As mentioned in the introduction, postpartum depression should be distinguished from postpartum blues, which recovers naturally within a few weeks after delivery. Although it has significance as a screening test for postpartum depression itself, a continuous follow-up for more than 6 months is required for accurate diagnosis and it should be reflected in future studies. Thirdly, psychiatric records such as the past history and family history of depression were not considered. These factors could affect the course and development of the disease and therefore it should be included in future studies. Finally, other demographic and socio-economic variables that could affect the study results were not sufficiently examined and considered for this study.

\section{CONCLUSION}

This study, targeting the mothers living in chungju examines the prevalence of postpartum depression and analyzed the correlation and odds-ratio of the education years and the number of children affecting the prevalence. This study has a significance in that it provides a clue for the treatment of postpartum depression for female in the community. We hope the results of this study helpful for future research as basic data.

\section{CONFLICTS OF INTEREST}

The authors have nothing to disclose.

\section{ACKNOWLEDGEMENTS}

Very special thanks to the staffs working at department of psychiatry in Konkuk university chungju Hospital. Without their support this work could not have been done.

\section{ORCID}

\author{
Ajin Yun \\ https://orcid.org/0000-0002-8877-6297 \\ Jeong-Seok Seo \\ https://orcid.org/0000-0002-4880-3684 \\ Beom-Woo Nam \\ https://orcid.org/0000-0003-3530-1746
}

\section{REFERENCES}

1. Lee J, Jang M. The mediating and moderating effects of parenting self-esteem on the relationship between parenting-role stress and depression among married women. Korea J Counc 2008;9:339-52.

2. Heinicke CM. Determinants of the transition to parenting. In: Bornstein $\mathrm{MH}$, ed. Handbook of parenting. Mahwah: Lawrence Erlbaum Associates; 1995. p. 277-303.

3. Belsky J, Pensky E. Marital change across the transition to parenthood. Marriage Fam Rev 1988;12:133-56. 
4. Smith LE, Howard KS. Continuity of paternal social support and depressive symptoms among new mothers. J Fam Psychol 2008;22:763-73.

5. Iles J, Slade P, Spiby H. Posttraumatic stress symptoms and postpartum depression in couples after childbirth: the role of partner support and attachment. J Anxiety Disord 2011;25:520-30.

6. Miller LJ. Postpartum depression. JAMA 2002;287:762-5.

7. Milgrom J, McCloud P. Parenting stress and postnatal depression. Stress Med 1996;12:177-86.

8. Whiffen VE. Is postpartum depression a distinct diagnosis? Clin Psychol Rev 1992;12:485-508.

9. Paffenbarger RS Jr, McCabe LJ Jr. The effect of obstetric and perinatal events on risk of mental illness in women of childbearing age. Am J Public Health Nations Health 1966;56:400-7.

10. O'Hara MW, Zekoski EM, Philipps LH, Wright EJ. Controlled prospective study of postpartum mood disorders: comparison of childbearing and nonchildbearing women. J Abnorm Psychol 1990;99:3-15.

11. Hendrick V, Altshuler L, Strouse T, Grosser S. Postpartum and nonpostpartum depression: differences in presentation and response to pharmacologic treatment. Depress Anxiety 2000;11:66-72.

12. Flanagan TJ, White H, Carter BG. Differential impairments in emotion face recognition in postpartum and nonpostpartum depressed women. J Affect Disord 2011;128:314-8.

13. Rutter M. Commentary: some focus and process considerations regarding effects of parental depression on children. Dev Psychol 1990;26:60-7.

14. Cummings EM, Davies PT, Simpson KS. Marital conflict, gender, and children's appraisals and coping efficacy as mediators of child adjustment. J Fam Psychol 1994;8:1419.

15. Murray L, Fiori-Cowley A, Hooper R, Cooper P. The impact of postnatal depression and associated adversity on early mother-infant interactions and later infant outcome. Child Dev 1996;67:2512-26.

16. Martins C, Gaffan EA. Effects of early maternal depression on patterns of infant-mother attachment: a meta-analytic investigation. J Child Psychol Psychiatry 2000;41:737-46.

17. Stein A, Gath DH, Bucher J, Bond A, Day A, Cooper PJ. The relationship between post-natal depression and motherchild interaction. Br J Psychiatry 1991;158:46-52.

18. Halbreich U, Karkun S. Cross-cultural and social diversity of prevalence of postpartum depression and depressive symptoms. J Affect Disord 2006;91:97-111.

19. Kelly R, Zatzick D, Anders T. The detection and treatment of psychiatric disorders and substance use among pregnant women cared for in obstetrics. Am J Psychiatry 2001;158:213-9.

20. Terry DJ, Mayocchi L, Hynes GJ. Depressive symptomatology in new mothers: a stress and coping perspective. $\mathrm{J}$ Abnorm Psychol 1996;105:220-31.

21. Kim YK, Won SD, Lim HJ, Choi SH, Lee SM, Shin YC, et al. Validation study of the Korean version of Edinburgh Postnatal Depression Scale (K-EPDS). J Kor Soc for Dep and Bip Disorders 2005;3:42-9.

22. Kim YK, Hur JW, Kim KH, Oh KS, Shin YC. Clinical application of Korean version of Edinburgh Postnatal Depression Scale. J Korean Neuropsychiatr Assoc 2008;47:36-44.

23. Yoshida K, Marks MN, Kibe N, Kumar R, Nakano H, Tashiro N. Postnatal depression in Japanese women who have given birth in England. J Affect Disord 1997;43:6977.

24. Lee DT, Yip SK, Chiu HF, Leung TY, Chan KP, Chau IO, et al. Detecting postnatal depression in Chinese women. Validation of the Chinese version of the Edinburgh Postnatal Depression Scale. Br J Psychiatry 1998;172:433-7.

25. Dankner R, Goldberg RP, Fisch RZ, Crum RM. Cultural elements of postpartum depression. A study of 327 Jewish Jerusalem women. J Reprod Med 2000;45:97-104.

26. Beck CT. Postpartum depressed mothers' experiences interacting with their children. Nurs Res 1996;45:98-104.

27. Wang SY, Jiang XY, Jan WC, Chen CH. A comparative study of postnatal depression and its predictors in Taiwan and mainland China. Am J Obstet Gynecol 2003;189:140712.

28. Mayberry LJ, Horowitz JA, Declercq E. Depression symptom prevalence and demographic risk factors among U.S. women during the first 2 years postpartum. J Obstet Gynecol Neonatal Nurs 2007;36:542-9.

29. Segre LS, O'Hara MW, Arndt S, Stuart S. The prevalence of postpartum depression: the relative significance of three social status indices. Soc Psychiatry Psychiatr Epidemiol 2007;42:316-21.

30. Hobfoll SE, Ritter C, Lavin J, Hulsizer MR, Cameron RP. Depression prevalence and incidence among inner-city pregnant and postpartum women. J Consult Clin Psychol 1995;63:445-53.

31. Righetti-Veltema M, Conne-Perréard E, Bousquet A, Manzano J. Risk factors and predictive signs of postpartum depression. J Affect Disord 1998;49:167-80.

32. Logsdon MC, Birkimer JC, Ratterman A, Cahill K, Cahill N. Social support in pregnant and parenting adolescents: research, critique, and recommendations. J Child Adolesc Psychiatr Nurs 2002;15:75-83. 